\title{
A New, Objective, Quantitative Scale for Measuring Local Skin Responses Following Topical Actinic Keratosis Therapy with Ingenol Mebutate
}

Robert Rosen • Ellen Marmur • Lawrence Anderson •

Peter Welburn · Janelle Katsamas

To view enhanced content go to www.dermtherapy-open.com

Received: February 3, 2014 / Published online: July 30, 2014

(C) The Author(s) 2014. This article is published with open access at Springerlink.com

\section{ABSTRACT}

Introduction: Local skin responses (LSRs) are the most common adverse effects of topical actinic keratosis (AK) therapy. There is currently no method available that allows objective characterization of LSRs. Here, the authors describe a new scale developed to quantitatively and objectively assess the six most common LSRs resulting from topical AK therapy with ingenol mebutate.

Methods: The LSR grading scale was developed using a 0-4 numerical rating, with clinical descriptors and representative photographic images for each rating. Good inter-observer

Electronic supplementary material The online version of this article (doi:10.1007/s13555-014-0059-9) contains supplementary material, which is available to authorized users.

R. Rosen $(\bowtie)$

Southderm Pty Ltd, 47 Regent Street, Kogarah,

NSW 2217, Australia

e-mail: skindoc@bigpond.net.au

E. Marmur

Mount Sinai School of Medicine, New York, USA

L. Anderson

Dermatology Associates of Tyler, Tyler, USA

P. Welburn · J. Katsamas

LEO Pharma Pty Ltd, Brisbane, Australia grading concordance was demonstrated in peer review during development of the tool. Data on the use of the scale are described from four phase III double-blind studies of ingenol mebutate $(n=1,005)$.

Results: LSRs peaked on days 4 (face/scalp) or 8 (trunk/extremities), with mean maximum composite LSR scores of 9.1 and 6.8, respectively, and a rapid return toward baseline by day 15 in most cases. Mean composite LSR score at day 57 was generally lower than at baseline.

Conclusion: The LSR grading scale is an objective tool allowing practicing dermatologists to characterize and compare LSRs to existing and, potentially, future AK therapies.

Keywords: Actinic keratosis; Dermatology; Ingenol mebutate; Local skin response; Quantitative scale; Severity assessment; Treatment outcome

\section{INTRODUCTION}

Actinic keratosis (AK) is a skin condition caused by excessive, prolonged exposure to ultraviolet 
light [1]. Topical treatments for $\mathrm{AK}$ include retinoids [2], colchicine [3], and, more commonly, several formulations of 5-fluorouracil, imiquimod, and diclofenac sodium 3\% gel $[4,5]$. Another approach is the use of ingenol mebutate gel, approved in the USA [6], European Union [7], Australia, Brazil, and Canada for the topical treatment of AK in adults. Each treatment offers specific advantages and disadvantages as well as potential complications. The most common resulting adverse effects (AEs) are local skin responses (LSRs) at the treatment area, categorized clinically as erythema, edema, erosion/ulceration, scabbing/crusting, weeping/ exudates, vesicles/pustules, and flaking/scaling/ dryness.

Historically, LSRs are graded subjectively $(0=$ none,$\quad 1=$ mild,$\quad 2$ = moderate, $\quad$ and $3=$ severe) [5]. During the clinical development of ingenol mebutate, the Food and Drug Administration (FDA) indicated that such subjective grading of LSRs was insufficient to quantify responses to a topically applied treatment [8]. It recommended the development of a quantitative tool for the assessment of LSRs, incorporating a photographic scale with numeric grades of severity, each of which should include clinical descriptors defining a particular level of response. The descriptors were to be sufficiently detailed to minimize inter-observer variability.

As a consequence, the LSR grading scale was developed. The scale has since been used in 15 AK studies of ingenol mebutate [9-15], assessing more than 1,900 cutaneous responses to treatment from 2006 to 2012 by at least 94 dermatologists [board certified (USA) or with equivalent certification in country of practice].

Here, the authors describe the development of the LSR grading scale and present pooled data from four pivotal phase III studies of ingenol mebutate [12] to illustrate the effective use of this scale for the objective assessment of LSRs.

\section{METHODS}

\section{Development of the LSR Grading Scale}

A requirement of the scale was that it should reflect multiple components of possible skin responses and separate expected skin responses from AEs that may be considered complications. Six reactions, namely erythema, flaking/scaling, crusting, swelling (edema), vesiculation/pustulation, and erosion/ ulceration, were selected to reflect typical LSRs seen with topical therapy. Characteristics of skin responses were identified and allocated a numeric grade of severity ( $0-4$, with 4 being the highest grade of severity) based on a concise written description, with specific parameters, and accompanied by a visual image of that level of severity (Fig. 1). No visual image of swelling was provided because of the difficulties associated with the effective photographic representation of different grades of this LSR.

The scores derived from the scale can be used in two ways. First, the individual LSR category score represents the type and time course of the skin response that a topical agent may cause during and after treatment. Second, the composite (total) numerical score of the individual LSRs for each patient provides a useful tool for analyzing the onset, peak, and resolution of the range of LSRs in treated patients. This composite LSR score (0-24) represents the sum of the scores graded from 0 to 4 on all six individual LSR categories.

The initial version of the scale was tested using a group of 36 Australian dermatologists 

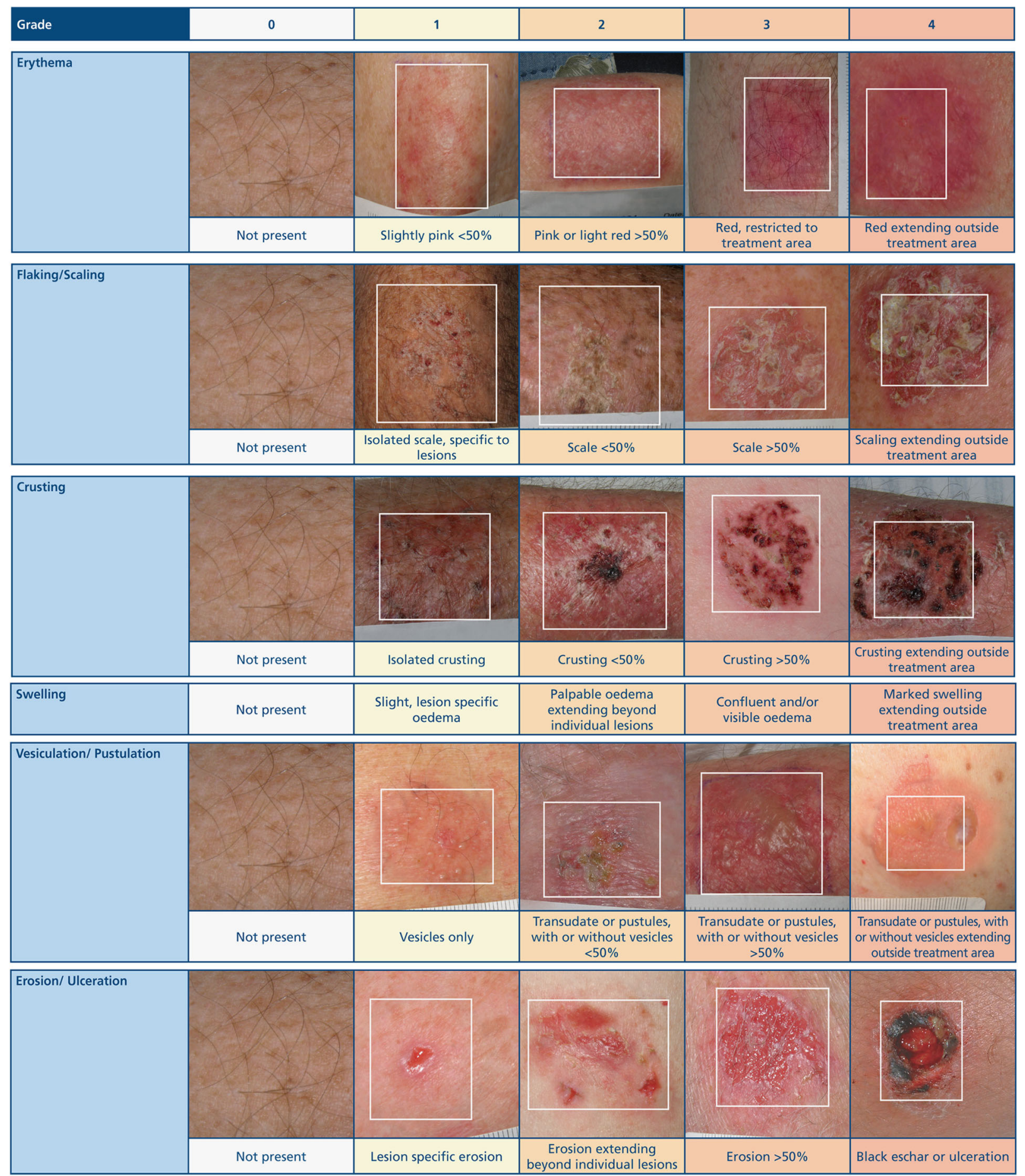

Fig. 1 Actinic keratosis. The LSR grading scale: a quantitative scale for the evaluation of LSRs arising from topical ingenol mebutate treatment. LSR Local skin response

at the Australian College of Dermatologists annual meeting, who were asked to grade a series of photographs of skin responses. These findings demonstrated good inter-observer grading concordance. The scale was subsequently tested by a group of approximately 
20 dermatologists attending a clinical investigators' meeting for ingenol mebutate in the USA. Good inter-observer concordance was again reported and minor changes were discussed and agreed to further enhance the reliability of the scale.

The final version of the LSR grading scale was introduced in December 2007 and was used in the pivotal ingenol mebutate clinical studies. In all trials, LSR evaluations were conducted by board-certified dermatologists at all assessment visits.

\section{Clinical Studies}

A total of 1,005 patients were randomized in two identical phase III, double-blind studies evaluating the treatment of AKs on the face/ scalp (PEP005-016, NCT00916006; PEP005-025, NCT00915551) and in another two identical phase III studies evaluating treatment of AKs on the trunk/extremities (PEP005-014, NCT00742391; PEP005-028, NCT00942604) [12]. Patients in the face/scalp studies $(n=547$, ITT population) applied ingenol mebutate $0.015 \%$ QD to a $25-\mathrm{cm}^{2}$ treatment area for three consecutive days $(n=277)$ or vehicle $(n=270)$ and those in the trunk/extremities studies $(n=458)$ applied ingenol mebutate $0.05 \%$ QD to a $25-\mathrm{cm}^{2}$ treatment area on the back, back of hand, arm, chest, shoulder or leg for two consecutive days $(n=226)$ or vehicle $(n=232)$. Composite LSR scores were calculated at each study visit for each patient [days 1 (baseline pre-treatment), 4, 8, 15, 29, and 57 for face/scalp; days 1 (baseline pre-treatment), 3, 8, 15,29 , and 57 for trunk/extremities].

\section{Compliance with Ethics Guidelines}

The analysis in this article is based on previously conducted studies, and does not involve any new studies of human or animal subjects performed by any of the authors.

\section{RESULTS}

\section{Studies of the Face/Scalp}

Figure 2 shows the time course of mean composite LSR scores for face/scalp treatment $(n=547)$ [12]. LSRs were transient and typically occurred within 1 day of therapy initiation, peaking in intensity up to 1 week following completion of treatment. These effects typically resolved within 2 weeks of therapy. Figure 3 shows representative examples of typical LSR progression by study visit, with resolution to a level lower than baseline by day 57. Erythema and flaking were the most common LSRs, with vesiculation and erosion occurring less commonly. Grade 4 vesiculation/erosion was only seen in $5 \%$ of patients.

The mean maximum composite LSR score over the entire study duration was 9.1 [standard deviation (SD, 4.1) for ingenol mebutate $0.015 \%$ versus 1.8 (SD, 1.6) for vehicle]. When patients were evaluated by complete clearance status or partial clearance, there was no correlation between clearance rate and mean maximum composite LSR score. In some patients, clearance was achieved with minimal composite LSR scores; in other patients clearance was achieved with no to little reported LSRs. A maximum composite LSR score greater than the baseline score was noted in $97.8 \%$ and $35.8 \%$ of patients treated with ingenol mebutate $0.015 \%$ and vehicle, respectively. Most patients $(81.8 \%)$ treated with ingenol mebutate $0.015 \%$ had their maximum composite LSR score at day 4 (Fig. 2).

Table 1 shows a summary of composite LSR scores for face/scalp treatment; Fig. 4 shows the 


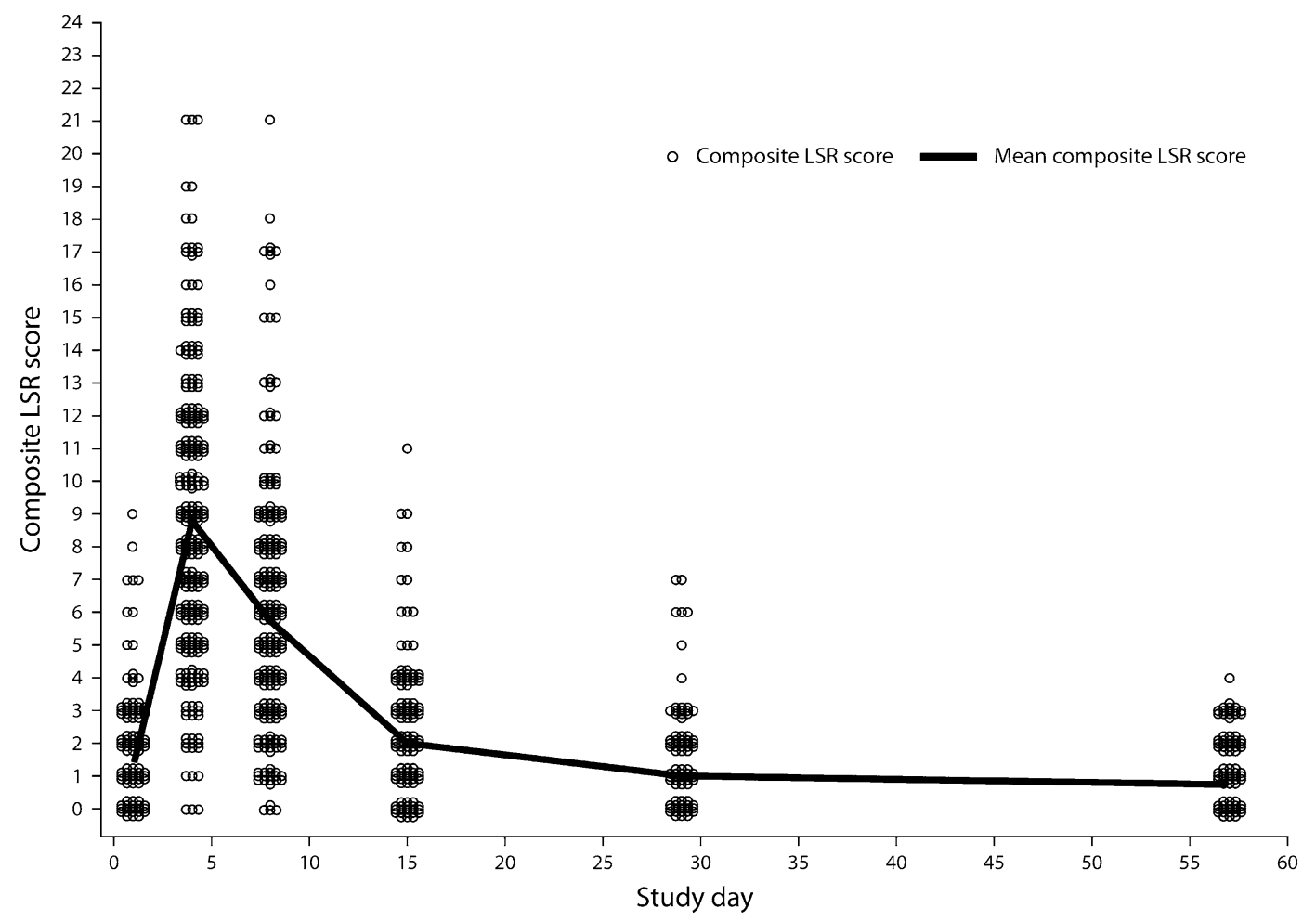

Fig. 2 Actinic keratosis. Time course of mean composite LSR scores in phase III face/scalp studies of patients treated with ingenol mebutate $0.015 \%$. LSR Local skin response

distribution of ingenol mebutate-treated patients who fell within each range of maximum composite LSR score (0-24). The majority of patients $(81.3 \%)$ with face/scalp lesions had maximum composite LSR scores between 1 and 12 . Only $1.8 \%$ of these patients had composite LSR scores in the most intense range (19-24). Most patients (99.3\%) in the vehicle group experienced a maximum composite LSR score between 0 and 12 . Table 2 shows maximum LSR scores for the face/scalp studies.

\section{Studies of the Trunk/Extremities}

The time course of the mean composite LSR score is shown in Fig. 5 for AK treatment on the trunk/extremities ( $n=458$, ITT population) [12]. LSRs were transient and typically occurred within 1 day of therapy initiation, peaking in intensity up to 1 week following treatment completion. These effects typically resolved within 4 weeks of therapy initiation [6]. Erythema and flaking were the most common LSRs; vesiculation and erosion occurred less commonly. Grade 4 vesiculation/ erosion was only seen in $1 \%$ of patients.

The mean maximum composite LSR score for patients given ingenol mebutate $0.05 \%$ was 6.8 (SD, 3.5) compared with 1.6 (SD, 1.5) for patients given vehicle. The maximum composite LSR score was higher than the baseline LSR score in $96.4 \%$ of patients receiving ingenol mebutate $0.05 \%$ and $31.0 \%$ of patients receiving vehicle. The maximum composite LSR score for patients treated with ingenol mebutate $0.05 \%$ occurred on day 3 for $55.1 \%$, on day 8 for $32.4 \%$, and on day 15 for 

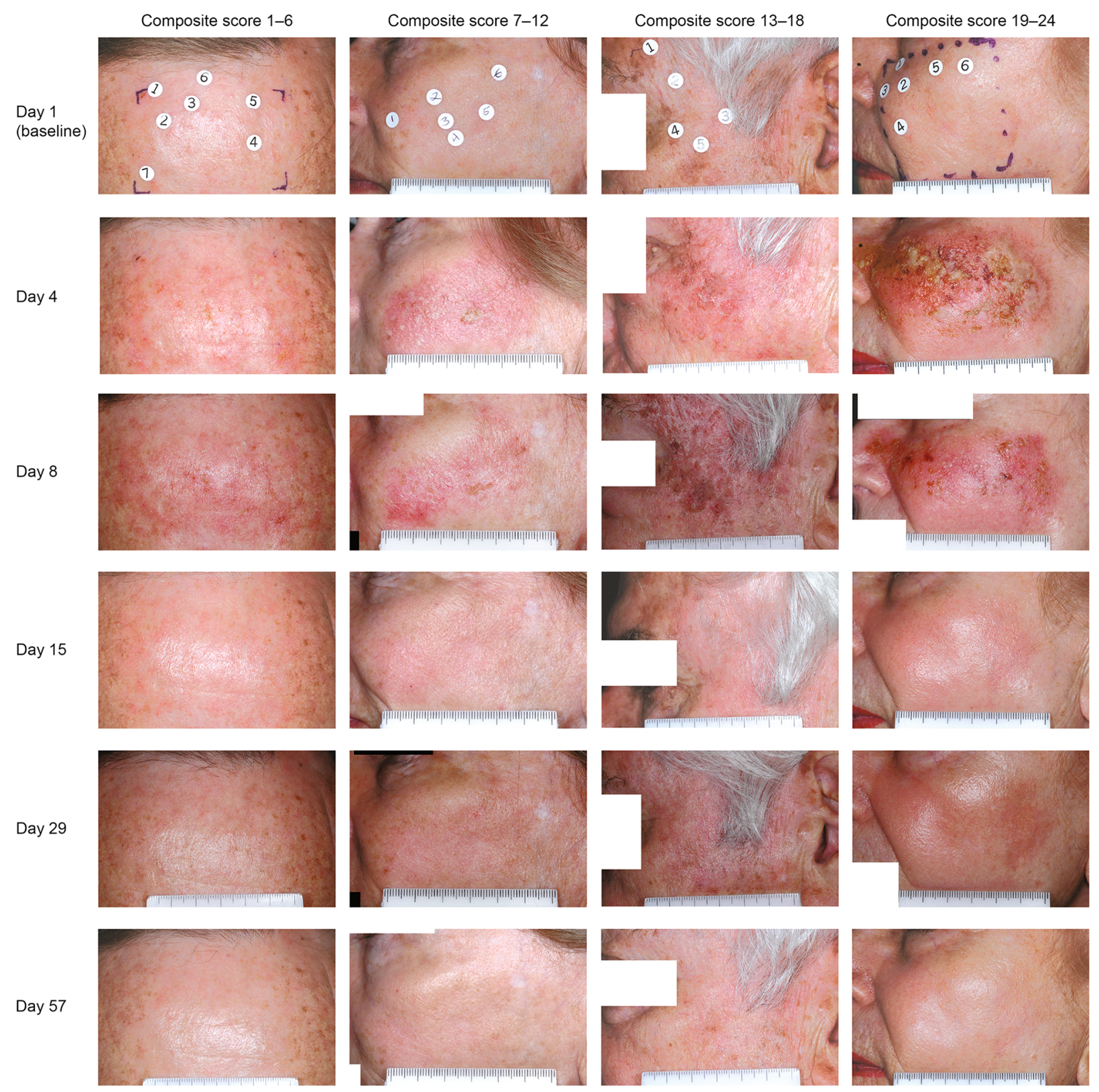

Fig. 3 Actinic keratosis. Patient photographs with varying composite LSR scores (range 1-24) for treatment on face/scalp are shown per visit from day 1 (baseline) to day 57. LSR Local skin response

$8.4 \%$ of patients. No patient experienced a maximum composite LSR score at day 29, although one (0.4\%) had a maximum composite LSR score at day 57. This patient's aberrant pattern of increasing LSR scores in the treatment area on the leg over the observation period may have been due to psoriasis, a pre- existing condition found in the treatment area by a post-study biopsy. No other abnormalities that might have accounted for this anomaly were reported in this patient.

Table 1 shows a summary of composite LSR scores for trunk/extremities locations; Fig. 4 shows the distribution of ingenol mebutate- 
Table 1 Summary of composite LSR scores in phase III studies (safety population)

\begin{tabular}{|c|c|c|c|c|}
\hline \multirow{2}{*}{$\begin{array}{l}\text { Summary of LSR composite } \\
\text { score }\end{array}$} & \multicolumn{2}{|l|}{ Face/scalp } & \multicolumn{2}{|l|}{ Trunk/extremities } \\
\hline & $\begin{array}{l}\text { Ingenol mebutate } 0.015 \% \\
(n=274)\end{array}$ & $\begin{array}{l}\text { Vehicle } \\
(n=271)\end{array}$ & $\begin{array}{l}\text { Ingenol mebutate } 0.05 \% \\
(n=225)\end{array}$ & $\begin{array}{l}\text { Vehicle } \\
(n=232)\end{array}$ \\
\hline Baseline score, mean (SD) & $1.4(1.5)$ & $1.1(1.2)$ & $1.0(1.2)$ & $1.1(1.3)$ \\
\hline $\begin{array}{l}\text { Maximum score post-baseline, } \\
\text { mean }(\mathrm{SD})^{\mathrm{a}}\end{array}$ & $9.1(4.1)$ & $1.8(1.6)$ & $6.8(3.5)$ & $1.6(1.5)$ \\
\hline $\begin{array}{l}\text { Patients with a score }>0, \\
n(\%)\end{array}$ & $272(99.3)$ & $199(73.4)$ & $223(99.1)$ & $158(68.1)$ \\
\hline $\begin{array}{l}\text { Patients with a } \\
\text { score }>\text { baseline, } n(\%)\end{array}$ & $268(97.8)$ & $97(35.8)$ & $217(96.4)$ & $72(31.0)$ \\
\hline \multicolumn{5}{|c|}{ Study day of maximum score, $n(\%)$} \\
\hline Number of scores $>$ baseline $^{b}$ & $5(1.8)$ & $174(64.2)$ & $8(3.6)$ & $160(69.0)$ \\
\hline Day $3 / 4$ & $224(81.8)$ & $34(12.5)$ & $124(55.1)$ & $32(13.8)$ \\
\hline Day 8 & $39(14.2)$ & $22(8.1)$ & $73(32.4)$ & $19(8.2)$ \\
\hline Day 15 & $4(1.5)$ & $18(6.6)$ & $19(8.4)$ & $11(4.7)$ \\
\hline Day 29 & $0(0.0)$ & $17(6.3)$ & $0(0.0)$ & $9(3.9)$ \\
\hline Day 57 & $1(0.4)$ & $6(2.2)$ & $1(0.4)$ & $1(0.4)$ \\
\hline
\end{tabular}

$L S R$ local skin response, $S D$ standard deviation

a The maximum composite LSR score is independent of time; it reflects the highest score at any time post-baseline

b All composite LSR scores post-baseline are below the baseline composite LSR score

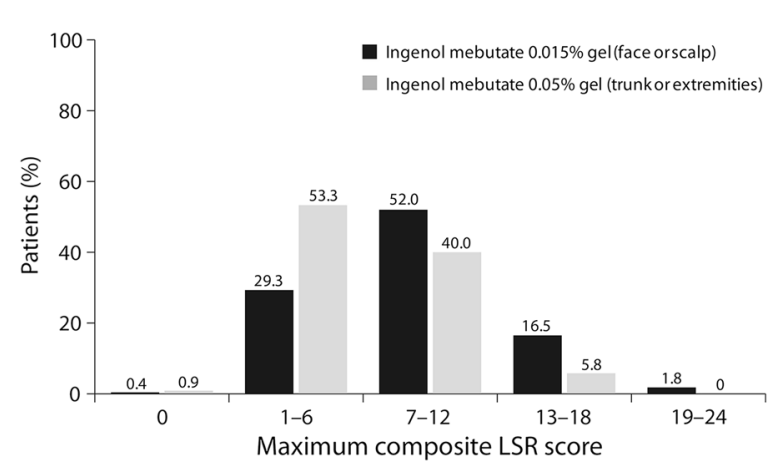

Fig. 4 Actinic keratosis. Distribution of maximum composite LSR scores in phase III studies (safety population). LSR Local skin response

treated patients who fell within each range of maximum composite LSR score (0-24). The majority of patients (93.3\%) with trunk/ extremity lesions treated with ingenol mebutate experienced a maximum composite LSR score between 1 and 12 . No patient in the study had composite LSR scores that exceeded 18. Most patients $(98.7 \%)$ in the vehicle group experienced a maximum composite LSR score of 0-6. Table 2 lists the maximum LSR scores in the trunk/extremities studies. Patient photographs with varying composite LSR scores (range 1-18) for treatment on trunk/ extremities are shown per visit from day 1 (baseline) to day 57 (Fig. 6).

\section{DISCUSSION}

LSRs are a common feature of the numerous ablative and non-ablative approaches to treat AK. These have generally been characterized as 
Table 2 Summary of the maximum score for each of the six individual LSRs post-baseline in phase III studies (safety population)

\begin{tabular}{|c|c|c|c|c|}
\hline \multirow[t]{2}{*}{ Maximum grade post-baseline } & \multicolumn{2}{|l|}{ Face/scalp } & \multicolumn{2}{|l|}{ Trunk/extremities } \\
\hline & $\begin{array}{l}\text { Ingenol mebutate } \\
0.015 \%(n=274)\end{array}$ & $\begin{array}{l}\text { Vehicle } \\
(n=271)\end{array}$ & $\begin{array}{l}\text { Ingenol mebutate } \\
0.05 \%(n=225)\end{array}$ & $\begin{array}{l}\text { Vehicle } \\
(n=232)\end{array}$ \\
\hline \multicolumn{5}{|l|}{ Erythema, $n(\%)$} \\
\hline 0 & $1(0.4)$ & $105(38.7)$ & $5(2.2)$ & $112(48.3)$ \\
\hline 1 & $25(9.1)$ & $127(46.9)$ & $31(13.8)$ & $102(44.0)$ \\
\hline 2 & $56(20.4)$ & $33(12.2)$ & $94(41.8)$ & $16(6.9)$ \\
\hline 3 & $125(45.6)$ & $6(2.2)$ & $61(27.1)$ & $2(0.9)$ \\
\hline 4 & $66(24.1)$ & $0(0.0)$ & $34(15.1)$ & $0(0.0)$ \\
\hline Any grade $>0$ & $272(99.3)$ & $166(61.3)$ & $220(97.8)$ & $120(51.7)$ \\
\hline \multicolumn{5}{|l|}{ Flaking/scaling, $n$ (\%) } \\
\hline 0 & $7(2.6)$ & $89(32.8)$ & $3(1.3)$ & $83(35.8)$ \\
\hline 1 & $52(19.0)$ & $142(52.4)$ & $52(23.1)$ & $131(56.5)$ \\
\hline 2 & $91(33.2)$ & $36(13.3)$ & $86(38.2)$ & $15(6.5)$ \\
\hline 3 & $98(35.8)$ & $4(1.5)$ & $66(29.3)$ & $3(1.3)$ \\
\hline 4 & $25(9.1)$ & $0(0.0)$ & $18(8.0)$ & $0(0.0)$ \\
\hline Any grade $>0$ & $266(97.1)$ & $182(67.2)$ & $222(98.7)$ & $149(64.2)$ \\
\hline \multicolumn{5}{|l|}{ Crusting, $n(\%)$} \\
\hline 0 & $44(16.1)$ & $219(80.8)$ & $50(22.2)$ & $188(81.0)$ \\
\hline 1 & $85(31.0)$ & $47(17.3)$ & $105(46.7)$ & $38(16.4)$ \\
\hline 2 & $64(23.4)$ & $5(1.8)$ & $39(17.3)$ & $4(1.7)$ \\
\hline 3 & $64(23.4)$ & $0(0.0)$ & $23(10.2)$ & $2(0.9)$ \\
\hline 4 & $16(5.8)$ & $0(0.0)$ & $8(3.6)$ & $0(0.0)$ \\
\hline Any grade $>0$ & $229(83.6)$ & $52(19.2)$ & $175(77.8)$ & $44(19.0)$ \\
\hline \multicolumn{5}{|l|}{ Swelling, $n(\%)$} \\
\hline 0 & $56(20.4)$ & $257(94.8)$ & $82(36.4)$ & $219(94.4)$ \\
\hline 1 & $88(32.1)$ & $12(4.4)$ & $65(28.9)$ & $13(5.6)$ \\
\hline 2 & $67(24.5)$ & $2(0.7)$ & $51(22.7)$ & $0(0.0)$ \\
\hline 3 & $48(17.5)$ & $0(0.0)$ & $20(8.9)$ & $0(0.0)$ \\
\hline 4 & $14(5.1)$ & $0(0.0)$ & $7(3.1)$ & $0(0.0)$ \\
\hline Any grade $>0$ & $217(79.2)$ & $14(5.2)$ & $143(63.6)$ & $13(5.6)$ \\
\hline \multicolumn{5}{|l|}{ Vesiculation/pustulation, $n(\%)$} \\
\hline 0 & $119(43.4)$ & $270(99.6)$ & $127(56.4)$ & $230(99.1)$ \\
\hline 1 & $36(13.1)$ & $1(0.4)$ & $46(20.4)$ & $1(0.4)$ \\
\hline 2 & $53(19.3)$ & $0(0.0)$ & $30(13.3)$ & $1(0.4)$ \\
\hline
\end{tabular}


Table 2 continued

\begin{tabular}{|c|c|c|c|c|}
\hline \multirow[t]{2}{*}{ Maximum grade post-baseline } & \multicolumn{2}{|l|}{ Face/scalp } & \multicolumn{2}{|l|}{ Trunk/extremities } \\
\hline & $\begin{array}{l}\text { Ingenol mebutate } \\
0.015 \%(n=274)\end{array}$ & $\begin{array}{l}\text { Vehicle } \\
(n=271)\end{array}$ & $\begin{array}{l}\text { Ingenol mebutate } \\
0.05 \%(n=225)\end{array}$ & $\begin{array}{l}\text { Vehicle } \\
(n=232)\end{array}$ \\
\hline 3 & $50(18.2)$ & $0(0.0)$ & $19(8.4)$ & $0(0.0)$ \\
\hline 4 & $15(5.5)$ & $0(0.0)$ & $3(1.3)$ & $0(0.0)$ \\
\hline Any grade $>0$ & $154(56.2)$ & $1(0.4)$ & $98(43.6)$ & $2(0.9)$ \\
\hline \multicolumn{5}{|l|}{ Erosion/ulceration, $n(\%)$} \\
\hline 0 & $186(67.9)$ & $267(98.5)$ & $167(74.2)$ & $226(97.4)$ \\
\hline 1 & $55(20.1)$ & $4(1.5)$ & $37(16.4)$ & $6(2.6)$ \\
\hline 2 & $26(9.5)$ & $0(0.0)$ & $15(6.7)$ & $0(0.0)$ \\
\hline 3 & $5(1.8)$ & $0(0.0)$ & $4(1.8)$ & $0(0.0)$ \\
\hline 4 & $1(0.4)$ & $0(0.0)$ & $2(0.9)$ & $0(0.0)$ \\
\hline Any grade $>0$ & $87(31.8)$ & $4(1.5)$ & $58(25.8)$ & $6(2.6)$ \\
\hline
\end{tabular}

LSR Local skin response

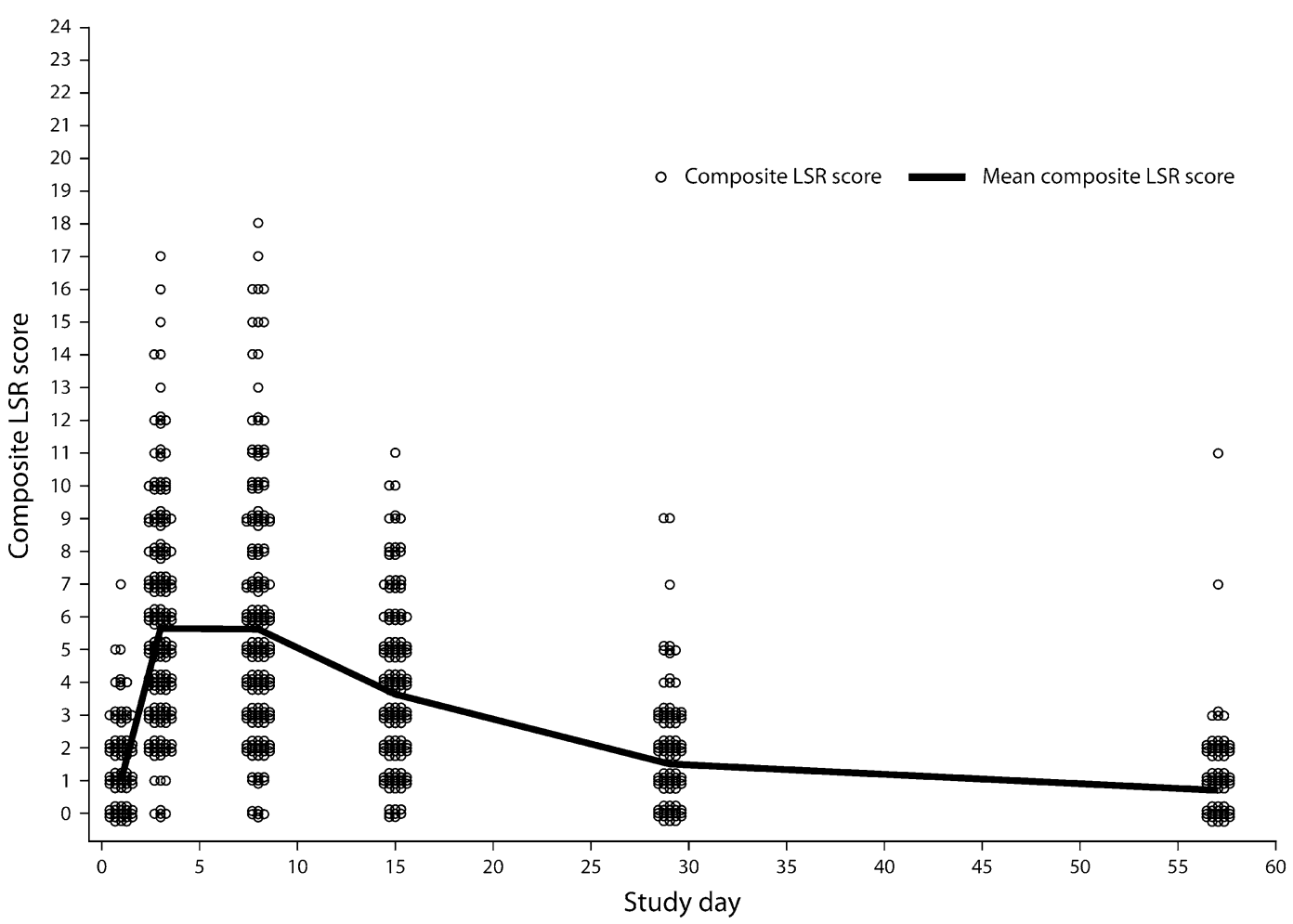

Fig. 5 Actinic keratosis. Time course of mean composite LSR scores in phase III trunk/extremities studies of patients treated with ingenol mebutate $0.05 \%$. LSR Local skin response 


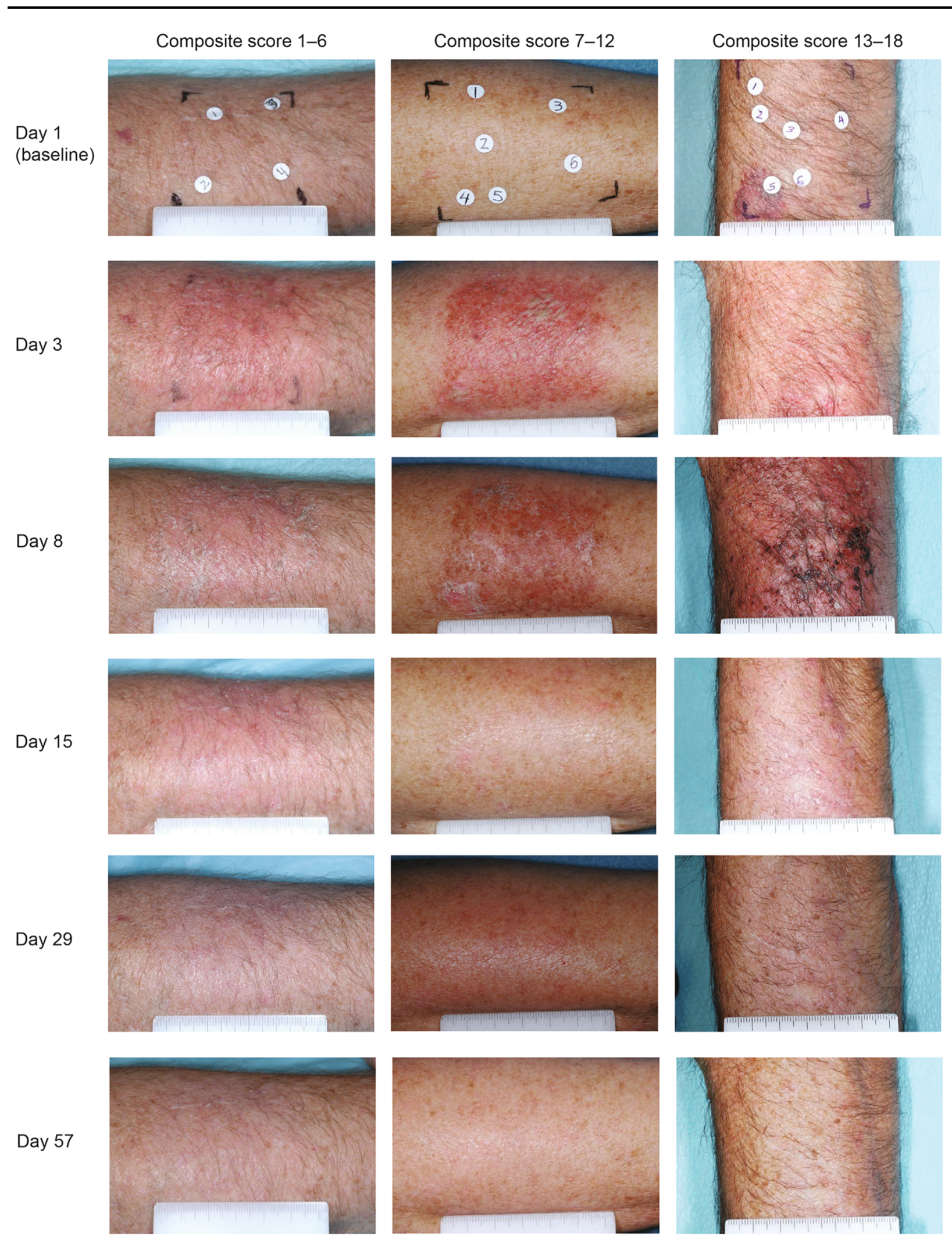

Fig. 6 Actinic keratosis. Patient photographs with varying composite LSR scores (range 1-18) for treatment on trunk/ extremities are shown per visit from day 1 (baseline) to day 57. LSR Local skin response 
mild, moderate, or severe, usually at the discretion of the investigator [5]. The LSR grading scale described here provides an objective and quantitative method for characterizing LSRs in patients receiving treatment with ingenol mebutate. The scale was shown to be associated with good interobserver grading concordance in peer review assessments.

In clinical studies of ingenol mebutate in AK, including the four phase III studies discussed here [12] and several phase I and II studies [9, $11,16,17]$, the scale effectively recorded the onset, maximum severity, and subsequent return to baseline for each one of six treatment-related responses and generated an overall composite score, taking all potential types of LSR into consideration. In the four phase III studies, the scale demonstrated that LSRs associated with ingenol mebutate during treatment for AK were transient, were detectable within 1 day of treatment initiation and peaked in intensity within the first week following completion of treatment. These effects generally resolved within 2 weeks of treatment initiation for areas on the face and scalp and within 4 weeks of treatment initiation for areas on the trunk and extremities; while exhibiting a longer peak than on the face and scalp, LSRs on the trunk and extremities were of a lower intensity [6, 12]. There was good reproducibility between the individual phase III studies. The tabular and graphic representations of LSR data presented here illustrate the ease with which rapid comparison of individual LSRs can be made and translated into a meaningful dialog with candidate patients for topical field therapy. More recently, the scale has been successfully used to assess LSRs in a first-in-man study of LEO43204 for topical treatment of AK on the forearms [18] and has also been used during treatment with ingenol mebutate for superficial basal cell carcinomas $[19,20]$.

Previous AK studies have not uniformly reported objectively the incidence, frequency, severity, or time course of LSRs, making comparison of the tolerability of different treatment modalities and dosing regimens difficult. This highlights the need for a standardized method of LSR assessment. To date, the LSR grading scale has not been used to assess LSRs with drugs other than ingenol mebutate and this is an area that merits investigation. It should be noted that the timing of LSR evaluations would need to be individualized based on the particular compounds under investigation because the time course of reactions differs for products with different treatment courses.

\section{CONCLUSION}

The objective, quantitative LSR grading scale described here provides clinicians with a valuable assessment tool. The ability to rate individual LSR categories (erythema, flaking/ scaling, crusting, swelling, vesiculation/ pustulation, and erosion/ulceration) and to generate a composite objective LSR score will enable dermatologists to compare the tolerability of current and future therapeutic modalities for AK in clinical trials and, potentially, real-world practice settings.

\section{ACKNOWLEDGMENTS}

The LSR grading scale was developed and used in studies of ingenol mebutate gel that were funded by Peplin Operations Pty Ltd (PEP005 studies) (Brisbane, Queensland, Australia). Sponsorship and article processing charges were funded by LEO Pharma A/S (Ballerup, 
Denmark). Medical writing services were provided by Paula Michelle del Rosario of iMed Comms (Macclesfield, UK) and were funded by LEO Pharma A/S (Ballerup, Denmark). All authors had full access to all of the data in this study and take complete responsibility for the integrity of the data and accuracy of the data analysis. All named authors meet the ICMJE criteria for authorship for this manuscript, take responsibility for the integrity of the work as a whole, and have given final approval for the version to be published.

Conflict of interest. R. Rosen serves on an advisory board and has been a consultant and a clinical investigator for LEO Pharma. R. Rosen has also been a clinical investigator and served on an advisory board for Galderma. E. Marmur has been a consultant for Roche, served on an advisory board for DUSA, and has been a speaker for Allergan. E. Marmur and L. Anderson have been clinical investigators in the ingenol mebutate clinical development program funded by LEO Pharma Pty Ltd (Australia) (formerly Peplin Operations Pty Ltd). L. Anderson has been a paid consultant to Peplin Inc., has served on the Peplin advisory board, and currently serves on the LEO Pharma A/S advisory board for ingenol mebutate gel. P. Welburn and J. Katsamas are employees of LEO Pharma Pty Ltd (Australia) (formerly Peplin Operations Pty Ltd).

Compliance with ethics guidelines. The analysis in this article is based on previously conducted studies, and does not involve any new studies of human or animal subjects performed by any of the authors.

Open Access. This article is distributed under the terms of the Creative Commons
Attribution Noncommercial License which permits any noncommercial use, distribution, and reproduction in any medium, provided the original author(s) and the source are credited.

\section{REFERENCES}

1. Salasche SJ. Epidemiology of actinic keratoses and squamous cell carcinoma. J Am Acad Dermatol. 2000;42:4-7.

2. Misiewicz J, Sendagorta E, Golebiowska A, Lorenc B, Czarnetzki BM, Jablonska S. Topical treatment of multiple actinic keratoses of the face with arotinoid methyl sulfone (Ro 14-9706) cream versus tretinoin cream: a double-blind, comparative study. J Am Acad Dermatol. 1991;24:448-51.

3. Grimaitre M, Etienne A, Fathi M, Piletta PA, Saurat $\mathrm{JH}$. Topical colchicine therapy for actinic keratoses. Dermatology. 2000;200:346-8.

4. Jorizzo JL. Current and novel treatment options for actinic keratosis. J Cutan Med Surg. 2005;8(Suppl 3):13-21.

5. Lebwohl $M$, Dinehart $S$, Whiting $D$, et al. Imiquimod 5\% cream for the treatment of actinic keratosis: results from two phase III, randomized, double-blind, parallel group, vehicle-controlled trials. J Am Acad Dermatol. 2004;50:714-21.

6. LEO Pharma. Picato ${ }^{\circledR}$ (ingenol mebutate) gel, $0.015 \%, 0.05 \%$. Prescribing information: www. picato.com/_pdf/PrescribingInformation.pdf. Last accessed February 6, 2014.

7. LEO Pharma. Picato 150 micrograms/gram gel. Summary of product characteristics: http://www. ema.europa.eu/docs/en_GB/document_library/EPA R_-_Product_Information/human/002275/WC500 135327.pdf. Last accessed April 26, 2013.

8. Food and Drug Administration (FDA). Memorandum of meeting minutes. Pre-phase 2 guidance meeting for IND 70,114, PEP005 topical gel for topical treatment of actinic keratoses. USA: FDA Communication; 2006.

9. Freeman M, Oakley A, Siller G, et al. Study to determine the optimal tolerated regimen of ingenol mebutate (PEPO05) gel for actinic keratosis of the face or face and scalp. Poster P2010 presented at the American Academy of Dermatology (AAD) Summer Academy Meeting, Chicago, IL, USA, July 30 to August 3, 2008. 
10. Spencer J. Multicenter, randomized, double-blind, vehicle-controlled, dose-ranging study to evaluate the efficacy and safety of PEP005 (ingenol mebutate) gel $0.005 \%, 0.01 \%$, and $0.015 \%$ when used to treat actinic keratoses on the head. J Am Acad Dermatol. 2010;62(3 Suppl 1):AB105 (Poster P2913).

11. Anderson L, Schmieder GJ, Werschler WP, et al. Randomized, double-blind, double-dummy, vehicle-controlled study of ingenol mebutate gel $0.025 \%$ and $0.05 \%$ for actinic keratosis. J Am Acad Dermatol. 2009;60:934-43.

12. Lebwohl M, Swanson N, Anderson LL, Melgaard A, $\mathrm{Xu} \mathrm{Z}$, Berman B. Ingenol mebutate gel for actinic keratosis. N Engl J Med. 2012;366:1010-9.

13. Steffen E, Bertsch HP, Haenssle HA, Zibert JR, Schön M, Schön MP. Pharmacodynamics of ingenol mebutate $0.05 \%$ gel for the treatment of actinic keratosis assessed by histology. J Am Acad Dermatol. 2013;68(4 Suppl 1):AB163 (Abstract P6969).

14. Ulrich M, Völker-Call M, Lange-Asschenfeldt S, et al. Assessment of the in vivo effects of ingenol mebutate $0.05 \%$ gel for the treatment of actinic field cancerization by reflectance confocal microscopy. Poster 334 presented at the 10th Meeting of the International Confocal Working Group (ICWG), Prague, Czech Republic, September 28, 2012.

15. Berman B, Swanson N, Goldenberg G, et al. Field treatment with ingenol mebutate gel, $0.015 \%$, 3 weeks after cryosurgery of actinic keratosis is safe and effective. Poster at the Winter Clinical Dermatology Conference of the American Academy of Dermatology, Koloa, HI, USA, January 18-23, 2013.

16. Ramsay JR, Suhrbier A, Aylward JH, et al. The sap from Euphorbia peplus is effective against human nonmelanoma skin cancers. $\mathrm{Br} \mathrm{J}$ Dermatol. 2011;164:633-6.

17. Spencer J. Multicenter, randomized, double-blind, vehicle-controlled, dose-ranging study to evaluate the efficacy and safety of PEP005 (ingenol mebutate) gel $0.005 \%, 0.01 \%$, and $0.015 \%$ when used to treat actinic keratoses on the head. Poster P2913 at the 68th Annual Meeting of the American Academy of Dermatology (AAD), Miami, FL, USA, March 5-9, 2010.

18. Sinnya S, McEniery E, Soyer HP, Tan J-M, Oesterdal ML. Safety of LEO 43204 in a first in man trial of actinic keratosis on the forearms. J Am Acad Dermatol. 2014;70(Suppl):AB139 (Abstract P7942).

19. Freeman M, Rosen R, Zibert JR, Knudsen KM, Spelman L. Ingenol mebutate gel topically applied under occlusion to superficial basal cell carcinoma is efficacious compared with marginal effect in seborrheic keratosis. J Am Acad Dermatol. 2014;70(Suppl):AB136 (Poster 7934).

20. Siller G, Rosen R, Freeman M, Welburn P, Katsamas J, Ogbourne SM. PEP005 (ingenol mebutate) gel for the topical treatment of superficial basal cell carcinoma: results of a randomized phase IIa trial. Australas J Dermatol. 2010;51:99-105. 